\title{
A APLICAÇÃo DA DIDÁTICA E DOS SABERES PEDAGÓGICOS AO ENSINO SUPERIOR
}

\section{Guilherme Assis de Figueiredo ${ }^{1}$}

\begin{abstract}
Resumo: Os professores do ensino superior durante a sua formação na pós-graduação stricto sensu não recebem os conhecimentos dos saberes pedagógicos e de didática. Em uma analise desta realidade verifica-se que a preocupação é tão somente na formação de pesquisadores quer no mestrado quer no doutorado, cabendo ao professor universitário proceder as suas aulas sem tais conhecimentos, tal realidade impacta negativamente o ensino e aprendizagem nos cursos de graduação. Neste contexto é que se tenta expor a realidade da docência no ensino superior e a legislação a respeito, bem como a necessidade da sua alteração.
\end{abstract}

Palavras-chave: Didática; Ensino superior; Formação de professores; Docência; Saberes pedagógicos.

\section{THE APPLICATION OF DIDACTICS AND PEDAGOGICAL KNOWLEDGE TO HIGHER EDUCATION}

\begin{abstract}
Teachers of higher education during their training in stricto sensu graduate programs do not receive the knowledge of pedagogical and didactic knowledge. In an analysis of this reality it is verified that the concern is only in the training of researchers as well as in the master's degree and doctorate, being the university professor to carry out his classes without such knowledge, such reality negatively impacts teaching and learning in undergraduate courses. In this context it is tried to expose the reality of teaching in higher education and the legislation in question, as well as the need to change it.
\end{abstract}

Keywords: Didactics; Higher education; Teacher training; Teaching; Pedagogical knowledge.

\footnotetext{
${ }^{1}$ Graduado em Direito pela Universidade Cândido Mendes Ipanema - UCAM, Especialização em Docência no Ensino Superior, Pontifícia Universidade Católica do Rio Grande do Sul-PUC/RS, especialista em Teoria do Estado, das Relações Privadas e Processo pela Escola de Magistratura de Mato Grosso do Sul/UNIGRAN, Especialista em Direito Civil e Processual Civil pela Universidade Para o Desenvolvimento da Região do Pantanal - UNIDERP. E-mail: figeoli@uol.com.br
} 


\section{1-Introdução:}

Para que um professor possa assumir uma sala de aula no ensino superior necessário se faz a adequada aplicação da didática, a qual pode ser considerada como uma matéria de integração entre todas as demais matérias, formando o conjunto de praticas escolares e conhecimentos que objetivam o desenvolvimento das habilidades cognitivas e operativas dos alunos, de acordo com a realidade social e material existentes, que resultarão na relação entre docência e aprendizado, qual seja, é a ação pedagógica-didática a ser aplicada, objetivando o desenvolvimento intelectual e capacidade cognitiva de forma independente e ativa do formando preparando-o para a vida social.

A didática tem em João Amós Cômenio (1562-1670) monge luterano, que autor da obra "Didática Magna - Tratado da arte universal de ensinar tudo a todos" o seu maior expoente, posto que pretendia ensinar tudo a todos sem excetuar ninguém, em contraposição a Igreja Católica que através da Companhia de Jesus pretendia a educação com os dogmas religiosos, sendo certo que encontramos em Cômenio os fundamentos para generalização do ensino para toda a população o que em síntese possibilitou a existência do capitalismo industrial no final do sec. XIX. A sua didática tinha como princípios a universalização da educação, a educação feita de acordo com o desenvolvimento natural do ser humano, o conhecimento é apropriado pela observação dos fenômenos e das coisas, através do método intuitivo do que se conhece para o que se quer aprender.

Os desafios da docência e da didática no ensino superior vão desde a formação do docente, as atualizações e treinamentos constantes inerentes à profissão e as novas tecnologias com a possibilidade de uso de tablet, smartphone, notebook aparelhos portáteis que unem o som, imagem e textos através de acesso da internet por wireless em sala de aula presencialmente ou no EAD Ensino a distância) com as AVAs (Ambiente virtual de aprendizagem) como o Moodle, Eureka, Sócrates e outros, possibilitando a interação professor-aluno no ensino à distancia ou mesmo presencialmente, com os recursos das instituições quer públicas quer privadas, disponíveis em sala de aula, o livro didático, as diferentes realidades socioculturais dos alunos e a necessidade de operar formas específicas de ensino, a necessidade do docente de ampliar os horizontes dos alunos para além do seu contexto sociocultural, estes são alguns dos desafios enfrentados pela docência e pela didática no ensino superior, bem como de todos aqueles que estão de alguma forma ligados ao processo, que várias abordagens e soluções são 
passiveis de aplicação, objetivando a formação de um profissional mais completo como pessoa em relação a sociedade em que vive.

Para que o professor possa realizar o seu trabalho de forma satisfatória é necessário que possua os instrumentos para tanto, qual seja, a técnica e a teoria em conjunto visando a prática adequada do ensino e conforme o contexto social em que esteja inserido com os seus alunos.

Não basta uma adequada formação do professor, necessário se faz que conheça e possa aplicar os instrumentos e materiais disponíveis de forma adequada o que somente se faz possível com o conhecimento específico da didática, não basta saber, tem que saber expor e entender como o seu aluno aprende, infelizmente a maioria das Universidades quer publicas quer privadas em seus cursos de mestrado não disponibilizam matérias atinentes à pedagogia e a didática na docência em ensino superior, raras exceções se visualizam, desta forma os professores irão tão somente cada um per si criar e seguir o que entendem como docência, culminando a que os professores universitários não tenham um conhecimento mínimo pedagógico (teoria da educação) ou didático (teoria do ensino).

O presente artigo foi elaborado com mapeamento bibliográfico, com método analítico e descritivo, tendo o Professor José Carlos Libâneo como referencial teórico.

O artigo pretende expor e tentar responder a seguinte problemática: a exigência legal da pós-graduação stricto sensu tão somente para o exercício da função de professor universitário, como tal limitação pode ser enfrentada visando a melhora do ensinoaprendizagem, na ausência dos saberes pedagógicos e da didática por parte dos professores universitários.

\section{2-O professor universitário:}

Um professor universitário seria um profissional das várias áreas como um advogado, um médico, um engenheiro que em momentos que não estão exercendo a sua profissão estariam lecionando, em sua grande maioria sim, são profissionais de mercado que lecionam em nossas Universidades, trazendo consigo a experiência e vivência na profissão, no entanto uma boa parte não possui formação no campo do que seja o ensino aprendizagem, sem formação pedagógica e sem conhecimento do que seja didática, a expansão recente do ensino superior levou a um aumento expressivo do número de docentes universitários segundo dados da Unesco 
em 1950 existiam 25 mil já em 1992 passaram para um milhão de professores universitários (UNESCO/CRESALC, 1996).

As preocupações quanto a formação do professor Universitário já foram objeto de legislação, as exigências mínimas foram estabelecidas pela LDBEN 9.394/96 (Brasil, 1996) em seu art.66 que estipula a necessidade de obtenção pelo docente de pós-graduação em programas de mestrado e doutorado e o Decreto 9.235/17 (BRASIL, 2017) em seu artigo 16, II o qual estabelece parâmetros relativos ao corpo docente na IES (Instituição de Ensino Superior) privadas, com o mínimo de 1/3 com titulação de mestres ou doutores, ou eventual reconhecimento de notório saber por parte da Universidade com curso de doutorado em área afim que pode suprir a exigência de título acadêmico específico, nos seguintes termos:

Art. 16- (Decreto 9.235/17)- As IES privadas poderão solicitar recredenciamento como centro universitário, desde que atendam, além dos requisitos gerais, aos seguintes requisitos:

II - um terço do corpo docente possuir titulação acadêmica de mestrado ou doutorado; (Decreto 9.235/17)

Art.66- (LDBEN- Lei 9.394/96)- A preparação para o exercício do magistério superior far-se-á em nível de pós-graduação, prioritariamente em programas de mestrado e doutorado.

Paragrafo único- O notório saber, reconhecido por universidade com curso de doutorado em área afim, poderá suprir a exigência de título acadêmico. (LDBEN-Lei 9.394/96).

O CAPES inicialmente pela circular 028/199 e posteriormente pela portaria 129 de 13/12/2006 (BRASIL, 2006) em seu art.19 determinou a obrigatoriedade do estágio de docência na formação de pós-graduandos, no entanto somente para os bolsistas PROSUP, bem como se trata de estágio de docência e não a uma efetiva formação teórica nos fundamentos da Pedagogia e da Didática inerentes ao ensino superior, com o que a sua aplicação e utilidade é muito limitada aos propósitos a que se pretendia. A USP através do PAE (Programa de Aperfeiçoamento de Ensino) criado em 1991 efetivas a formação do futuro docente no ensino superior em seus cursos de pós-graduação stricto sensu através da PP (Preparação Pedagógica) e do ESD (Estágio Supervisionado de Docência) o qual serviu de base para a CAPES estender o Programa de Estágio Docente a todas as Universidades Públicas do país.

[...]Art. 19. O estágio de docência é parte integrante da formação do pós-graduando, objetivando a preparação para a docência, a qualificação do ensino de graduação e será obrigatório para todos os bolsistas do PROSUP, obedecendo aos seguintes critérios (CAPES-Portaria 129 de 13/12/2006, acesso em 05/09/18) 
A legislação somente delimita os critérios para ingresso na docência universitária e não com o necessário processo de formação continuada do docente para a sua permanência no cargo, no entanto a obtenção de grau de mestre ou doutor não garante um conhecimento mínimo pedagógico (teoria da educação) ou didático (teoria do ensino) inerentes ao exercício de tal mister, neste sentido Selma Pimenta leciona em seu livro Docência no Ensino Superior (PIMENTA, 2014, p.36), nos seguintes termos:

[...] o professor universitário aprende a sê-lo mediante um processo de socialização em parte intuitiva, autodidata ou (...) seguindo a rotina dos "outros". Isso se explica, sem duvida devido a inexistência de uma formação específica como professor universitário. Nesse processo, joga um papel mais ou menos importante sua própria experiência como aluno, o modelo de ensino que predomina no sistema universitário e as reações dos alunos, embora não há que se descartar a capacidade autodidata do professorado. Mas ela é insuficiente. (PIMENTA, 2014, p.36)

Portanto a formação acadêmica e experiência profissional do docente não o preparam efetivamente para o ingresso em sala de aula sem o conhecimento do que seja o processo cientifico de ensino-aprendizagem, gerando os mais variados resultados, culminando pela inexistência de controle institucional ou vacilante cobrança pelas instituições do que foi lecionado.

As Autoras Valéria Belletati e Isaneide Domingues (BELLETATI, DOMINGUES, 2015, p.159) afirmam que há uma verdadeira negação e falta de aplicação dos conhecimentos pedagógicos e da didática culminando em uma formação de professores que necessita de mudanças dada as suas fragilidades, posto que ao docente cabe muito mais do que ensinar conteúdos, mas promover uma emancipação intelectual e política com o que denominam didática crítica, nos seguintes termos:

[...] No que se refere à formação de professores para o ensino superior, mais especificamente dos docentes de cursos de graduação. Não há exigência legal de formação pedagógica. O que conta são os cursos de pós-graduação, experiência profissional, publicação de pesquisa, conforme especificidades do curso e da profissão para qual forma.

A priorização de conhecimentos específicos e de metodologias na formação de professores e o pouco investimento das políticas públicas e, muitas vezes dos docentes na garantia de espaços de reflexões critica e criativa sobre o ensino, em todos os níveis, contribuem para a negação dos conhecimentos pedagógicos para o exercício da docência.[...] (BELLETATI, DOMINGUES, 2015, p.159)

O professor José Carlos Libâneo, (LIBÂNEO, 2013, p.27) indica que a formação profissional do professor é dada pela conjunção de duas dimensões, a primeira seria a formação teórica-cientifica, e a segunda seria a formação pedagógica, aliando-se assim a formação 
acadêmica com os conhecimentos da Filosofia, Sociologia e demais matérias, incluído a didática, acrescidos dos contextos sociais e políticos inerentes a sociedade em que se está inserido.

É certo que a educação deve ser considerada um processo e um fenômeno social, neste sentido a formação do professor deve estar fortemente vinculada com o seu compromisso ético e social para com a sociedade, deve o mesmo se empenhar para preparar cidadãos participativos na sociedade em que está inserido, em todas as suas dimensões, quer no seio de sua família, no seu trabalho, na politica, visando a obtenção e manutenção das conquistas democráticas, para tanto deve prover o seu aluno dos conhecimentos básicos e habilidades necessárias para munilo das condições de enfrentar as lutas da vida prática junto a sociedade, no seu trabalho, na vida social e politica.

[...] As disciplinas de formação técnico-prática não se reduzem ao mero domínio de técnicas e regras, mas implicam também os aspectos teóricos, ao mesmo tempo que fornecem à teoria os problemas e desafios da prática. A formação profissional do professor implica, pois, uma contínua interpenetração entre teoria e prática, a teoria vinculada aos problemas reais postos pela experiência prática e a ação prática orientada teoricamente. [...] (LIBÂNEO, 2013, p.27)

São estas as dimensões em que a formação do professor é esperada, dentro das limitações pessoais e de materiais inerentes às dificuldades econômicas que a educação no Brasil vive.

Portanto não há processo de aprendizagem que sejam apartados dos contextos sociais a que os alunos estejam integrados, cabendo a sensibilidade do docente em além de entender estas realidades, proceder a expansão da realidade sócio cultural existente do aluno, expondo e demonstrando a existência de outras realidades, as quais os alunos estarão interagindo no futuro, como muito bem leciona o Professor Hélio Mangueira de Almeida, (ALMEIDA, 2015, p.3).

[...] É importante também que o professor assuma a função de criar situações para momentos de questionamentos, desacomodações, propiciando situações de desafios a serem vencidos pelos alunos, para que possam construir conhecimentos e aprender além do seu meio social, com amplitude de conhecimentos onde não se sintam engessados à realidade fora do seu cotidiano. (ALMEIDA, 2015 p.3)

Em outro tipo de subdivisão é dada por Maurice Tardif que divide em quatro os saberes profissionais dos professores, tais saberes seriam temporais, plurais e heterogêneos, personalizados e por fim que tais saberes carregariam a marca do ser humano, seriam temporais os saberes dos professores posto que somente pudessem ser adquiridos através do tempo, com a bagagem trazida pelo professor e temporais por serem os primeiros anos de profissão muito importantes na estruturação de sua prática profissional.

Rev. de Pesquisa e Educação Jurídica | e-ISSN: 2525-9636 | Porto Alegre | v. 4 | n. 2 | p. 18 - 34 | Jul/Dez. 2018 
Os saberes seriam plurais e heterogêneos porque os professores teriam formações personalíssimas, com conhecimento disciplinar e cultura pessoal, bem como porque não há uma unificação dos saberes inerente a profissão de professor, dependendo a sua aplicação e escolha de ferramentas de acordo com os objetivos pretendidos em cada sala de aula. Os saberes seriam personalizados posto que apropriados e incorporados pelo professor enquanto ser humano com sua história de vida, suas experiências no trabalho docente e sua personalidade.

Os saberes carregariam a marca do ser humano porque o seu trabalho é com seres humanos, com suas particularidades e individualidades, que se traduzem na motivação dos alunos à aprender, talvez a mais importante e complicada das tarefas do professor. Maurice Tardif (TARDIF, 2014, p.276) afirma que é necessário que os professores realizem pesquisas sobre as suas próprias práticas de ensino, para que haja os necessários questionamentos sobre os saberes profissionais dos professores.

[...] acreditamos que já é tempo de os professores universitários da educação, começarem também a realizar pesquisas e reflexões críticas sobre suas próprias práticas de ensino. Na Universidade temos com muita frequência a ilusão de que não temos práticas de ensino, que nós mesmos não somos profissionais do ensino ou que nossas práticas de ensino não constituem objetos legítimos para a pesquisa. Este erro faz com que evitemos os questionamentos sobre os fundamentos de nossas práticas pedagógicas, em particular nossos postulados implícitos sobre a natureza dos saberes relativos ao ensino. Não problematizada, nossa própria relação com os saberes adquire, com o passar do tempo, a opacidade de um véu que turva nossa visão e restringe nossas capacidades de reação. (TARDIF, 2014, p.276)

O Professor José Carlos Libâneo (LIBÂNEO, 2001, p.8) que é o referencial teórico deste artigo, muito bem expõe que o aluno vive em sociedade com um conteúdo cultural e social que interferem na sua aprendizagem, cabendo ao professor tentar entender estas diferentes realidades, posto que estas mudam no espaço em que se está e no tempo em que se vive, portanto os processos de aprender e pensar dependem dos contextos socioculturais, cabendo a didática operar formas específicas de ensino.

[...] O ponto de vista defendido aqui é de os alunos podem ser intencionalmente ensinados a pensar, em contextos sócio culturais específicos. Nesse sentido, os processos do aprender a pensar e do aprender a aprender, além de estarem vinculados à psicologia da aprendizagem e do desenvolvimento, dependem também da consideração dos contextos socioculturais. (LIBÂNEO, 2001, p.8)

A docência no ensino superior na presente data possui também como um dos seus desafios a utilização das novas tecnologias por parte dos professores, entre elas a graduação e pós-graduação ofertadas em EAD (Ensino a distância), modalidade esta que teve início em 1880 através de estudo por correspondência, sendo que o primeiro curso superior foi ofertado em 
1881 nos EUA pela Chautauqua Correspondece College, já em 1930, havia 39 universidades norte americanas que ofereciam cursos por correspondência, (BITTNER, MALLORY, 1933, p.31) e relataram “... cerca de 2 milhões de alunos matriculados todo ano, quatro vezes o número de todos os alunos matriculados em todas as faculdades e escolas dos Estados Unidos.". Seguiram-se ao ensino por correspondência a transmissão por rádio e tv, teleconferência e internet web. Só para compararmos com a realidade brasileira em 2009 havia um milhão de alunos universitários em EAD, atualmente temos 5 milhões de alunos por EAD, dados do ano de 2014, havendo o incremento de 1 milhão de alunos a cada ano (ABED, 2015).

Os AVAs (Ambientes Virtuais de Ensino) já são uma realidade nos cursos em ambiente EAD tais como o Moodle, Eureka, Sócrates e outros, possibilitando a interação professor-aluno no ensino à distancia. As novas tecnologias chegam a graduação presencial com aparelhos portáteis como tablete, notebook, smartphone, com flexibilidade de acesso por wireless, permitindo a convergência digital de imagem, som e texto, encontrando alunos que são verdadeiros nativos digitais e professores que na grande maioria são migrantes digitais, bem demonstrando que há necessidade de treinamento dos professores para o uso das novas tecnologias, neste sentido leciona Vani Moreira Kenski (KENSKI, 2013, p.70).

[...]A imagem da IES como provedora de um ensino de qualidade e moderno é apresentada pela divulgação de imagens de salas de aula, laboratórios e demais instalações repletas de computadores. Grandes investimentos são realizados para a incorporação de sistemas de tele e vídeo conferências, acessos a ambientes virtuais de alta complexidade e usos de computadores pelos alunos em aulas presenciais.

No entanto, o avanço tecnológico não foi articulado com mudanças estruturais no processo de ensino, mas propostas curriculares e na formação dos professores universitários para a nova realidade educacional. Em muitos casos, as IES iniciaram programas de capacitação para o uso dos novos equipamentos, mas as práticas pedagógicas permaneceram as mesmas ou retrocederam. (KENSKI, 2013, p.70).

Desta forma os professores universitários apesar de usarem as novas tecnologias não detém o integral conhecimento de suas potencialidades, neste sentido Marta Garcia afirma "não é possível vivenciar na prática aquilo que se desconhece, tampouco é possível promover a aprendizagem de conteúdos que não se domina." (GARCIA, 2011, P.80) (Rev.Teoria e Prática da Educação, v.14, n.1, p.80, jan./abr. .2011), devendo se empreender esforços para transpor tais barreiras e limitações como se oportunidades para o processo ensino-aprendizagem o fossem, uma vez que não mais retornaremos ao quadro negro e ao giz tão somente, outrossim, seja qual seja a nova tecnologia e elas se sucedem no tempo com os avanços e desenvolvimento de novos materiais e softwares, havendo sim uma interação cada vez maior entre o presencial 
e o virtual, com o inicio do conteúdo em sala de aula seguindo-se de complementação por textos, vídeos, em ambiente virtual, a ser acessado pelo aluno universitário em hora e momento mais adequado, permitindo a que a aula restrita de meros 50 minutos seja complementada com novos conhecimentos, enfim, o que se vislumbra para o futuro é que nunca irá mudar é a necessidade de conhecimento dos saberes pedagógicos e da didática ao professor universitário, posto que o uso de novas tecnologias se dá como um suporte e não como ferramenta.

Estes são alguns dos desafios diários dos professores e de todos aqueles que estão de alguma forma ligada ao processo de ensino aprendizagem, que como exposto várias abordagens e soluções são passiveis de aplicação, no entanto ainda seguimos sem uma solução efetiva quanto a formação dos professores universitários, na qual tivessem os saberes pedagógicos e da didática inerentes a docência no ensino superior, e até mesmo falta novo treinamento para inserção das novas tecnologias em sala de aula, objetivando a formação de um aluno universitário mais completo como pessoa em relação a sociedade em que vive.

\section{3-A didática no ensino superior:}

A didática é uma disciplina da Pedagogia, que efetiva o fazer pedagógico em várias extensões tais como a técnica, a social e a politica, objetivando o incremento cognitivo dos conhecimentos sistematizados, ao analisarmos a evolução da pedagogia e da didática no Brasil verificamos as suas tendenciais que podem ser divididas em duas correntes a as de cunho liberal como a Pedagogia Renovada e Tecnicismo Educacional, a Pedagogia Tradicional e as de cunho progressista como a Pedagogia Crítico-Social dos Contextos e a Pedagogia Libertadora.

Na corrente de cunho liberal dada pela Pedagogia Tradicional, cabe ao professor o papel central, que expõe a matéria sendo a Didática uma mera disciplina que regula o ensino, com mera memorização do conteúdo, a Pedagogia Renovada engloba várias correntes, montessoriona, piagetiana e outras, tem no movimento Escola Nova ou Didática Ativa que é compreendida como a direção da aprendizagem, cabe ao professor colocar o aluno a que busque per si o conhecimento, com os estímulos, orientações e condições propicias buscando sempre um aluno ativo e investigador, para a Didática Ativa neste caso são importantes os trabalhos em grupo, pesquisas, experiências, projetos, visando sempre processos de aprendizagem que possibilitem o desenvolvimento do aluno, é a orientação da aprendizagem. 
A Pedagogia Tecnicista Educacional pode ser inserida na Pedagogia Renovada, ela se preocupa com o uso de meios e técnicas eficazes, neste caso o professor é o executor e administrador do planejamento e dos meios de se chegar aos objetivos.

Na corrente de cunho progressista dada pela Pedagogia Libertadora a Didática não possui uma proposta explicita, sendo concebida como uma visão tecnicista, prescritiva e instrumental, as atividades são centradas em questões politicas e sociais as quais são objeto de discussões destas realidades.

Para a Pedagogia Crítico-Social dos Conteúdos visa a participação de todos nas lutas sociais cabendo a educação a função da formação politica e social de acordo com a vida concreta dos alunos, neste caso a Didática possui grande importância visando a que o aluno tenha o domínio de conteúdos científicos para que formem consciência critica em uma auto atividade em relação as realidades sociais vividas, sendo este um agente ativo na transformação da sociedade, esta ultima é a corrente pedagógica de José Carlos Libâneo que é o referencial teórico deste artigo.

Vários são as contribuições sobre a docência e a didática no ensino superior, entre eles destacamos as autoras Selma Pimenta e Lea Anastasiou (PIMENTA, 2014, p.71) ao analisarem o ensino da didática concluem pela sua necessária aplicação para que o ensino aprendizagem se faça possível, o mais importante também exposto pelas autoras é que a didática advém dos vários saberes inerentes ao exercício da profissão, entre eles os saberes da experiência a qual se demonstra essencial ao professor tendo em vista as mais variadas e possíveis realidades e contextos encontrados pelos professores, daí decorrem os mais diversificados desafios.

Neste contexto, da mesma forma que Maurice Tardif, indica a pesquisa realizada por parte dos próprios professores como imperiosa quando se pretende evoluir na didática, posto que somente se pesquisando, conhecendo e expondo à todos que se interessam pelo assunto se pode efetivamente evoluir em novos saberes na didática, notadamente quando há a inserção de novas tecnologias em sala de aula e no EAD (Ensino a distância) obtendo até mesmo novas configurações de programas para a área, posto que são as necessidades da prática que irão dar as configurações dos saberes, com a ressignificação da didática e da docência .

[...]Em nosso entendimento, nos processos de formação de professores, é preciso considerar a importância dos saberes das áreas de conhecimento (ninguém ensina o que não sabe), dos saberes pedagógicos (pois o ensinar é uma prática educativa que que tem diferentes e diversas direções de sentido na formação do humano), dos saberes didáticos (que tratam da articulação da teoria da educação e da teoria do ensino para ensinar nas situações contextualizadas) dos saberes da experiência (do sujeito professor (que dizem do modo como nos apropriamos do ser professor em nossa vida). Esses saberes se 
dirigem às situações de ensinar e com elas dialogam, revendo-se, redirecionando-se, ampliando-se e criando.(PIMENTA, 2014, p.71).

Selma Pimenta, ao analisar a necessidade dos saberes pedagógicos e da didática no ensino superior para a docência no artigo "É possível formar professores sem os saberes da pedagogia? Uma reflexão sobre docência e saberes" em conjunto com Amanda Marques, ambas questionam a importância dos saberes pedagógicos para que os professores procedam a docência com tais saberes científicos, visando o desenvolvimento da autonomia intelectual do aluno, para que este desenvolva o seu processo de conhecimento, formando pessoas, formando cidadãos. Maurice Tardif ao analisar a concepção de saberes da docência indica o professor como um produtor de saberes em especial pela junção entre a teoria e a prática do professor e também pela pesquisa, visando uma revisão das lógicas formativas dos professores unicamente pela formação universitária, ao mesmo tempo não indica quais seriam os saberes para a docência, mas tão somente faz uma análise das características dos saberes docentes, sem um aprofundamento de como se constrói através da teoria e da ciência da educação tais saberes docentes.

Os saberes necessários a docência seriam os conteúdos das diversas áreas do saber, os didáticos e pedagógicos, conforme leciona Selma Pimenta (PIMENTA, MARQUES, 2015, p.142) e os relacionados a sensibilidade humana, que seria o sentido da existência humana, portanto necessário ao professor ter o conhecimento das formas de ensinar e conheça como o aluno aprende, tendo consciência das inter-relação de sua matéria com todas as demais e qual projeto formativo irá orientar as suas ações de forma a que sejam profissionais críticos e reflexivos de sua atividade docente em face das exigências sociais e politicas inerentes:

[...] Vale lembrar que a prática docente é condicionada por exigências, sociais, políticas e ideológicas (LIBANEO, 1994), uma vez que toda prática educativa é parte integrante da dinâmica social. No contexto atual, cabe a escola preparar o estudante para o mundo do trabalho, formar o cidadão para a intervenção na vida pública, prevalecendo a segunda função sobre a primeira. (PIMENTA, MARQUES, 2015, p.142)

Neste mesmo artigo as Autoras explicitam o que seria a didática, como a ação docente que englobaria "relação professor-aluno, projeto politico-pedagógico, planejamento do trabalho docente, currículo, avaliação, formas de organização de agrupamentos, entre outros são temas da didática" (PIMENTA, MARQUES, 2015, p.150). Essa estrutura conceitual e metodológica dos conteúdos requer um profundo conhecimento por parte do professor aliando a teoria da educação (conhecimento pedagógico) com a teoria do ensino (didática), a qual a autora Pimenta 
dá o nome de didática multidimensional, para que não se tornem tão somente uma tecnologia à disposição, mas um conjunto, um todo, que possibilite ao professor analisar e decidir visando a realização de um projeto formativo mais amplo dos alunos e que efetivamente extrapola a sala de aula:

[...] No campo específico da Didática, há muito se superou uma Didática instrumental (que reduzia o ensino à sua dimensão técnica, e a formação de professores ao treinamento de habilidades) em direção a uma Didática fundamental (CANDAU, 1984) pautada na concepção de ensino em suas dimensões política, humana e técnica. Hoje, pode-se falar em uma Didática multidimensional (PIMENTA et al, 2014) considerando o ensino como fenômeno complexo e multirreferencial, que extrapola a sala de aula e que se constitui à luz dos saberes da Pedagogia enquanto articuladores de múltiplas dimensões e análises do fenômeno. (PIMENTA, MARQUES, 2015, p.150)

Valéria Belletati e Isaneide Domingues afirmam que o ensino bem com a didática não são neutras, estas refletem as finalidades educacionais, decorrente de cada sociedade, portanto ambas são intencionais e indicam o vinculo político e social no qual tanto a instituição como o professor estão inseridos (BELLETATI, DOMINGUES, 2015, p.174), em tal contexto uma postura crítica e reflexiva pode ensejar a criação de novas formas de fazer, posto que a didática tão somente fornece os meios para reflexão da sua atividade docente, cabendo aos professores fazer a transformação. Algumas das questões da didática seriam o como, o que, para que e porque ensinar utilizando os fundamentos teórico-práticos do relacionamento para com outras disciplinas pedagógicas tais como Filosofia, Sociologia e Psicologia como subsidio à educação e outras áreas afins, posto que a didática seria como que uma "lente multifocal".

[...] A Didática é uma lente multifocal que nos ajuda a olhar a prática docente e o sentido de ensinar, a sair da zona de conforto das práticas pedagógicas generalistas e a conceber novas relações com o saber. Ela nos aproxima da prática vivida e favorece a invenção e a criação de novos fazeres.

Para uma reflexão crítica, há necessidade de se recorrer ás teorias educacionais, á Pedagogia que nos fornecem perspectivas de análises da realidade educativa e não respostas aos nossos problemas cotidianos. Estas nós mesmos devemos buscar, tendo clareza das finalidades de nosso trabalho e buscando meios para conseguir atingi-los, sem nunca nos considerarmos satisfeitos com os resultados obtidos. (BELLETATI, DOMINGUES, 2015, p.174).

Os desafios da docência no ensino superior exigem saberes pedagógicos, posto que na presente data os professores universitários se preparam para serem pesquisadores na pósgraduação stricto sensu, faltando os saberes pedagógicos e didáticos a formação de cidadãos críticos, conscientes e preparados para atuarem na sociedade como agentes transformadores é tarefa das mais difíceis, é nesse sentido o posicionamento de Terezinha Azeredo Rios, "A 
universidade é um espaço em que se articulam o ensino, a pesquisa e a extensão, com a finalidade de formar profissionais críticos e criativos, capazes de construir, com seu trabalho uma sociedade democrática e solidária.” (RIOS, 2009, p.119).

O Professor José Carlos Libâneo, relaciona uma série de operações didáticas, as quais podem ser divididas em três etapas e que requerem habilidades específicas dos professores, que seriam: a fase de planejamento, a fase de direção de ensino e a fase de avaliação, cada qual com as suas particularidades, devendo o professor, no caso o professor universitário possuir o domínio de cada uma das fases para que a direção do ensino e da aprendizagem se faça possível.

Entre os vários aspectos de cada uma das três fases expostas por Libâneo, será exposto um aspecto tão somente de cada fase para melhor compreensão, da fase do planejamento sobressai a necessidade de conhecimento e domínio dos vários métodos de ensino e procedimentos didáticos para que possa fazer a escolha do melhor deles de acordo com as características dos alunos. Da direção do ensino, é importante saber integrar os conteúdos e métodos de cada uma das disciplinas para com os princípios da aprendizagem, da avaliação se requer do professor além do efetivo domínio dos instrumentos de avaliação a que após obter dados de rendimento possa caso necessário reformular o tipo de avaliação e ensino para que os resultados sejam satisfatórios. Desta forma, todas estas atividades que na verdade são o cotidiano do professor universitário necessitam dos saberes pedagógicos e de um profundo conhecimento da didática LIBÂNEO, (2013, p.78,79), sem os quais não se pode realizar as suas tarefas docentes a contento.

[...]Estes são alguns dos requisitos de que necessita o professor para o desempenho de suas tarefas docentes e que formam o campo de estudo da Didática. Evidentemente, as mesmas expectativas que o professor tem em relação ao desenvolvimento intelectual dos alunos aplica-se a ele próprio.

A didática assim, oferece uma contribuição indispensável à formação dos professores, sintetizando no seu conteúdo a contribuição de conhecimentos de outras disciplinas que convergem para o esclarecimento dos fatores condicionantes do processo de instrução e ensino, intimamente vinculado com a educação e, ao mesmo tempo provendo os conhecimentos específicos necessários para o exercício das tarefas docentes. (LIBÂNEO, 2013, p.78,79)

A Didática que é uma disciplina da Pedagogia e no caso do ensino superior não é objeto de estudo na pós-graduação Stricto sensu quer no mestrado quer no Doutorado, os quais são os pré-requisitos para a docência no ensino superior, cabendo ao professor universitário proceder as suas aulas sem tais conhecimentos. Não existem soluções em nossa legislação atualmente para solucionar tal lacuna, existindo tão somente algumas soluções isoladas como o do projeto 
da USP o PAES, ou a inserção de matérias de saberes pedagógicos e da didática por parte da UCDB em MS, nos seus cursos de pós-graduação stricto sensu, o debate e a exposição de tais fragilidades em nosso ensino superior é medida que se impõe, visando a formação de cidadãos críticos, conscientes e preparados para atuarem na sociedade como agentes transformadores desta.

No presente ano ocorreram algumas alterações na LDBEN, estas fazem referência a várias matérias e assuntos, no entanto em nenhum momento tais alterações se efetivaram no sentido de prover o docente dos saberes pedagógicos ou da didática, mantendo inalterado o art.65 da LDBEN (BRASIL, 1996) que dispensa o pós-graduando de prática de ensino docente inclusive.

\section{4-Considerações finais:}

Os saberes pedagógicos e a didática que é uma disciplina da pedagogia não são objeto de estudo por parte dos professores universitários em sua formação, como exposto acima leciona Libâneo que é o referencial teórico deste artigo tais saberes são necessários para a fase de planejamento, fase de direção de ensino e fase de avaliação dos alunos universitários, devendo o professor ter domínio de cada uma das fases o que somente é possível com os saberes pedagógicos e da didática. Foi exposto o programa PAE da USP que serviu de base para a alteração dada pela portaria 129 de 13/12/2006 do CAPES que instituiu a aplicação de estágio de docência aos pós-graduandos, mas tão somente aos bolsistas PROSUP, bem como não há uma formação teórica efetiva, culminando a que os professores universitários não tenham um conhecimento mínimo pedagógico (teoria da educação) ou didático (teoria do ensino).

As novas tecnologias são um dos desafios a serem enfrentados pelos professores, na graduação e pós-graduação ofertadas em EAD e presencial, onde os AVAs possibilitam a interação professor-aluno no ensino à distancia e também no ensino presencial, as novas tecnologias chegam a graduação e pós-graduação presencial ou EAD com aparelhos portáteis como tablete, notebook, smartphone, exigindo treinamento dos professores para o uso das novas tecnologias, de qualquer forma seja qual seja a nova tecnologia para o futuro o que nunca irá mudar é a necessidade de conhecimento dos saberes pedagógicos e da didática por parte do professor universitário, posto que o uso de novas tecnologias se dá como um suporte e não como ferramenta, objetivando a formação de um aluno universitário mais completo como 
pessoa em relação a sociedade em que vive, para que possa ser instrumento de transformação desta.

A importância da Didática e dos saberes pedagógicos no ensino aprendizagem nas universidades se sobressaem da exposição dos pensamentos dos vários Autores acima citados, verifica-se que tal lacuna não só pode como deve ser preenchida talvez com futuras alterações legislativas inserindo a Didático também como pré-requisito para a docência no ensino superior, mas enquanto não há qualquer movimento neste sentido, apresento o que seria uma singela proposta para atenuar provisoriamente as limitações dos professores universitários, qual seja, a possibilidade dos professores universitários receberem suporte dos professores de Pedagogia da graduação e pós-graduação da sua própria universidade para que lecionem, expondo as suas dificuldades em sala de aula, sendo auxiliado em suas ações docentes e até mesmo caso tenham interesse ou seja necessário possam cursar como aluno ouvinte a matéria de Didática quer presencial quer por EAD, com o que se veria talvez superada algumas das limitações atualmente existentes no ensino aprendizagem do ensino superior, até que haja uma melhor regulamentação legislativa efetivamente satisfatória à respeito, permitindo avanços educacionais expressivos onde impera a estagnação.

\section{Referências bibliográficas:}

ABED, 2015 - Associação Brasileira de Ensino à distância, disponível em http://abed.org.br/arquivos/Censo_EAD_2015_POR.pdf, acesso em 05/09/18.

ALMEIDA, Hélio Mangueira, A Didática no Ensino Superior: Práticas e Desafios, p.3, Revista Estação Científica - Juiz de Fora, nº 14, julho - dezembro / 2015.

BELletATI, DOMINGUES, Valéria Cordeiro Fernandes, e Isaneide, Da negação da didática à didática crítica, Revista Metalinguagens, n3, 2015, p.159, acessado em 01/09/18. , Fernandes, Valéria Cordeiro, e Isaneide, Da negação da didática à didática crítica, Revista Metalinguagens, n3, 2015, acesso em 01/09/18.

BITTNER, W.S. \& Mallory, H. F. 1933, p.31, University Teaching by email, New York: Macmillan. 
BRASIL, Ministério da Educação, Lei 9.394/96 de 13/12/1996, Lei de Diretrizes e Bases do Ensino, art.66, disponível em http://www.planalto.gov.br/ccivil_03/leis/L9394.htm, acesso em 08/09/18.

Decreto 9.235/17 de 15/12/17, art. 16, II, Regulação, supervisão e avaliação dos cursos superiores e pós-graduação no sistema federal de ensino, disponível em http://www. planalto.gov.br/ccivil_03/_Ato2015-2018/2017/Decreto/D9235.htm, acesso em 08/09/18.

Coordenação de Aperfeiçoamento de pessoal de Nível Superior- CAPES, portaria 129 de 13/12/2006, Regulamento do Programa de Suporte à Pós-Graduação de Instituições de Ensino Particulares art.19, disponível em https://www.capes.gov.br/images/stories/download /relatorios/Portaria_PROSUP.pdf, acesso em 08/09/18.

GARCIA, Marta, 2011, Novas Competências Docentes Frente às Tecnologias Digitais Interativas, Rev. Teoria e Prática da Educação, v.14, n.1, p.80, jan./abr. .2011.

KENSKI, Vani Moreira, Tecnologias e tempo docente, Campinas /SP, 2013, Editora Papirus, 2013.

LIBÂNEO, José Carlos, 2001, O essencial da didática e o trabalho do professor - Em busca de novos caminhos, disponível em http://limaribeiro.net/File/Content/Document/ptbr/didatica-do-ensino-superior-o-essencial-da-didatica.pdf, acesso em 08/09/18.

LIBÂNEO, José Carlos, Didática, Editora Cortez, São Paulo, 2013, 2 edição, p.27. , José Carlos, Didática, Editora Cortez, São Paulo, 2013, 2 edição, p.78,79. José Carlos, O Essencial da Didática e o Trabalho de Professor- Em busca de novos caminhos, site https://moodle.pucrs.br/pluginfile.php/2299914/mod_resource/content /2/Did\%C3\%A1tica\%20-\%20Lib\%C3\%A2neo.pdf, acessado em 17/11/17.

PIMENTA, Selma Garrido, ANASTASIOU Léa das Graças Camargos, Docência no Ensino Superior, 2014, São Paulo/SP, Cortez Editora, 5 edição. Selma Garrido, ANASTASIOU Léa das Graças Camargos, Docência no Ensino Superior, 2014, São Paulo/SP, Cortez Editora, 5ª edição, 2014. , Selma Garrido e MARQUES, Amanda Cristina Tegno Lopes, É possível formar professores sem os saberes da pedagogia? Uma reflexão sobre docência e saberes, Revista 
metalinguagens número 3 de Maio de 2015, p.142, disponível em file://C:/Users/ DELL/ Downloads/65-155-PB\%20(2).pdf, acesso em 08/09/18.

, Selma Garrido e MARQUES, Amanda Cristina Tegno Lopes, É possível formar professores sem os saberes da pedagogia? Uma reflexão sobre docência e saberes, Revista metalinguagens número 3 de Maio de 2015, p.150 ISSN- 2358-2790, disponível em file:///C:/ Users/ DELL /Downloads/65-155-PB\%20(2).pdf, acesso em 08/09/18.

RIOS, Terezinha Arruda, Ética da docência universtitária: Apontamentos para um diálogo, In: CUNHA, M. I., et al (Orgs.) Docência universitária: profissionalização e praticas educativas, Feira de Santana, UEFS, Editora, 2009.

TARDIF, Maurice, Saberes docentes e formação profissional, Petrópolis/RJ, Editora Vozes, $17^{\mathrm{a}}$ edição 2014.

UNESCO/CRESALC. Situación de la educación superior em America Latina y Caribe. Kingston (Jamaica): VII Conferência Regional de Ministros de Educación, 1996. 